\title{
Do College Accounting Curriculums Teach To The CPA Exam? Should They?
}

Martin Rudnick, (E-mail: Rudnick@wpunj.edu), William Paterson University Virginia Anne Taylor, (E-mail: TaylorV@wpunj.edu), William Paterson University

\section{Introduction}

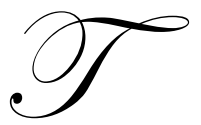

here has always been tremendous pressure on accounting programs throughout the United States to ensure the success of their graduates. Success can be measured through various forms of outcomes assessment. However, for accounting students the most common and universally accepted outcome is the pass rate of graduates on the uniform Certified Public Accounting (CPA) exam. Due to intense pressure to obtain a decent "pass rate", many accounting programs have been designed to "help" the students with the CPA exam. In order to examine this issue, our focus question is whether or not this should be the direction of accounting curriculums. In other words, do accounting courses teach toward the CPA exam? Should they?

In the first area of this paper we will address the question: what are the necessary tools needed to pass the CPA exam. In conjunction with this investigative section we will cite the required course work mandated by various states to sit for the CPA exam. Accordingly we will define whether or not the CPA exam's new 150-credit requirement has aided accounting curriculums in providing these necessary tools needed to pass the CPA exam.

The second section of this research paper considers both how courses are taught and how students are tested in the classroom. It then examines the adequacy of the current distribution of the required business and accounting credit requirements and includes a discussion of whether the current testing models are consistent with what is needed for students to pass the CPA exam. The questions examined are what is offered in the college classroom and more importantly, is this what should be offered in the classroom.

Finally we will discuss the role of the outside independent CPA review or prep courses. Is this the only place where the accounting student should expect to prepare for the CPA exam or is the college classroom an appropriate place to offer preparation? We will examine how a CPA review course prepares its students. This means we will determine what the focus of the accounting review course is, and are the college accounting curriculums offering the similar programs for it students. Finally we will summarize our findings as to whether or not the typical accounting program is teaching to the CPA exam.

\section{The Necessary Tools Needed To Pass The CPA Exam}

The AICPA mandated in 2000 that all candidates for the CPA exam must have completed a minimum of 150 credit hours. Forty three jurisdictions offering the CPA exam have complied with these criteria as of this date. It is interesting to note that one of the largest states as to currently licensed CPA's, New York does not yet require 150 credits to sit for the CPA exam. New York is not mandating the 150 credit requirement until 2009. Additionally Colorado rescinded the 150 credit requirement within six months of its initial adoption.

The distribution of college credit requirements within the states and jurisdictions licensing CPA's tend to make up a common core. That common core exists regardless of whether or not is it a " 150 " state. Forty-eight credits in accounting and business courses is the general standard. This is equal or in some cases greater then the curriculum specifications of most states and jurisdictions that have adopted the 150 -credit requirement. The breakdown of accounting usually normally requires 24 to 30 credit hours of accounting. Most jurisdictions require two introductory courses in accounting, followed by two courses or the equivalent of Intermediate Financial Accounting. After the completion of Intermediate Accounting the normal requirement is one to two courses in cost or managerial accounting, one to two courses in Taxation, Advanced Accounting and Auditing. It is interesting to 
note that although Non-Profit Accounting (Governmental and Non-Profit entities) is tested in some detail on the CPA exam, not one jurisdiction offering the exam requires a course in Non-Profit Accounting.

A further review of the requirements of the states and jurisdictions which have adopted the 150-credit requirement only Florida has significantly increased the number of credits in accounting and/or business related courses. A few other states added three to six credits to the accounting or business related course requirements. Even with the additional requirements not one of the jurisdictions offering the CPA exam require a not for profit accounting course. At most the accounting student is exposed to two or three chapters in an advanced accounting course. This does not completely cover the material tested on the CPA exam in the in this area.

Other Business credits are usually included in the forty-eight credit requirement. Most states require three to six credits in business law. Although business law is now being combined with taxation in the new Regulation section of the exam the scope of material covered on the exam is not changing. Those jurisdictions that only require one three-credit course in business law are not providing the student with the necessary background for the CPA exam. Even when two law classes have been completed, coverage of commercial code law is often inadequate for the CPA exam.

The newest section of the CPA exam, Business Environment and Concepts covers material normally taught in Microeconomics and Corporate Finance. At this time it is not certain if the material that will be covered is sufficient for the exam. Since this is a departure from the material that has been covered in the past, one must question whether or not the student will be properly prepared. Accounting curriculums require further revisions to accommodate this change. As of now there is no set requirement in most states that address this new section of the CPA exam. Most jurisdictions, New Jersey as an example, require three to six credit hours of Economics and Finance however they do not specify the courses that must be taken. A student could chose from a number of courses in these fields. It was not a problem for the accounting student who was focusing on becoming a CPA in the past, but it is now. As of April 5, 2004 this will be necessary to pass the CPA exam.

This brings us back to the initial question. Are students given the necessary tools (via required curriculum) to pass the CPA exam? The new 150-credit requirement did not increase the required coursework in accounting and business. The CPA exam demands knowledge in the areas of economics and finance. The CPA exam also requires knowledge in the area of non-profit accounting. Some states and jurisdictions offering the CPA exam do not require specific coursework that addresses these requirements. In conclusion, let us add one more very important fact. According to the National Association of State Boards of Accounting (NASBA) only 30\% an average of the candidates sitting for any one part of the CPA exam pass ( passing grade is 75\%) that part. This is one of the lowest passing rates of any professional licensing exam in the United States. It is now easy to conclude, in our opinion, the curriculums of most colleges and universities do not give students all the tools needed to pass the CPA exam. If they did would not the pass rates on the CPA exam be higher?

\section{How Students Are Taught And Tested In The Classroom}

There are a variety of methods to teach and test students in the classroom. Our concern is do these teaching and testing methods prepare our students for the outside world. More importantly do they give our students the tools necessary to be successful on the uniform CPA exam? Some will argue that we are not to become a "trade school" where the only importance is placed on the eventual licensing of our graduates in the field of public accountancy. While we agree this is a very valid concern we must also ask the question. How do potential employers evaluate accounting programs at various colleges and universities? In numerous discussions that we have had with human resource and services staff of local, regional and national CPA firms in the greater New York metropolitan region there has been one overriding question. Do your graduates have a good track record on the CPA exam? On further questioning these individuals feel that a good passing track record equates with an accounting program that produces high quality graduates.

The last paper and pencil CPA exam was given this past November. No longer will candidates sit twice per year at the same time and date to take the CPA exam. As of April 5, 2004 the CPA exam in each and every 
jurisdiction will be available the first two months of each quarter in the calendar year. Candidates will request a date during these two months at a computer test site. This is a major departure from the method in which the exam was always given. The exam will be taken on a computer and the candidate will not be allowed to use any other tools such as scrap paper or a hand held calculator to assist in answering questions.

Another departure from the old CPA exam format is the type of questions that will be used. Eighty percent of the credit will come from multiple choice type questions. The remaining twenty- percent of the credit will be from simulations. These simulations will represent cases and problems typical in the real world according to the American Institute of Certified Public Accountants (AICPA). The AICPA prepares the exam and grades the exam for the fifty-four states and jurisdictions in which it is offered. According the AICPA's web site the new exam is intended to reflect real world applications.

In order to prepare our accounting students for the CPA exam as well as what is required in the real world the use of computers in the classroom is imperative. The laptop and the desktop computer are the primary and in most cases the only tool that today's CPA uses. The paper worksheets of the past are history. All work is done via the computer in today's business world. This makes it imperative that the computer be fully utilized in the classroom. This is not just to prepare students for the CPA exam. This will prepare students for the business world. By incorporating computer applications into today's business and accounting curriculum we are preparing our students for life outside the university. This is a most necessary tool. The use of computer applications by accounting students is not a trade school concept. It is the only practical method to prepare today's graduate for the licensing exam and the business world.

The computer based CPA exam is comprised of four different parts. In each part eighty percent of the credit is from multiple choice questions. The remaining twenty percent of the credit will be from simulations. These simulations are cases in which the candidate will write essay answers, prepare or complete worksheets. The candidates will be given reference tables, statistical data and resource materials. They will be expected to research the questions from the data banks and incorporate their results in their answers.

Considering the new test format of the CPA exam should we try to gear our in class testing towards this format? Instructors use various testing methods in the classroom. Most professors do not want to be accused of running a CPA review course in their classroom. However using multiple choice and similar case method testing is not turning the classroom into a CPA review course. It has been common practice for many professors to use questions that have appeared on past CPA exams on their own progress examinations. What we are suggesting is to continue this testing method. Time usually does not permit exams to cover the many areas to be tested unless there is a combination of multiple choice and case type questions. By following this testing method the student can demonstrate their knowledge of the material and it will help prepare them for the licensing exam (CPA exam) upon graduation.

\section{The Role Of Outside Independent CPA Review Courses}

Independent CPA review courses are offered throughout the United States. The largest CPA review course, Becker/Convisor Professional Review has been in business since the early sixties. Becker/Convisor offers classes throughout the United States. There are a number of smaller courses that offer CPA review either locally or regionally. What Becker/Convisor and the local CPA review course have in common is a proven success rate for their students. The national average pass rate for any one part of the CPA exam is thirty percent. Becker/Convisor has a pass rate that is nearly two and a half times the national average and most local and regional courses have the similar success.

CPA review courses summarize the information that will be covered on the CPA exam. As an instructor of CPA review courses (Person/Wolinsky CPA Review) and editor of materials for CPA review it is easy to point out the differences between the college classroom and the CPA review course. The CPA review course only covers that which has been tested on past CPA exams. The material covered on the CPA exam can only skim the surface of what is covered in the college classroom. The financial accounting portion of the CPA exam is four hours in length. 
Financial accounting tests what is normally covered in two intermediate accounting courses and the material normally covered in advanced accounting. Assuming an instructor tests their students an average of three times per semester for the three different courses this can add up to between twelve and sixteen hours of testing or more. This must be condensed into only four hours for CPA exam testing. Therefore the CPA exam can only skim the surface in order to cover the various areas that must be tested. This is the focus of a CPA review course. Teach only what will be tested on the CPA exam. Summarize the material.

The focus of a CPA review course is very simple. Give the student what they need to pass the exam. No more, but no less then what is necessary. Becker CPA Review covers the financial accounting section of the CPA exam in nine, four- hour classes. The material that is covered in at least three, three to four credit classes is summarized in thirty-six hours. CPA review is much different then the college classroom. The review course's mission is to "review" that which has been taught in the college classroom. Furthermore the CPA review course only covers material which has a high probability of appearing on the licensing exam.

\section{Conclusions}

Therefore to summarize our findings. The classroom and the CPA review are quite different. Although we are not advocating the focus of the classroom is to teach to the CPA exam. We are stating that the classroom is where the student should be given the necessary tools to pass the exam. These tools include the coursework that covers the material tested on the exam. Additionally we feel classroom emphasis on tested materials and follow up simulations that use progressively more complex issues could be integrated into classroom and homework assignments with no detriment to traditional learning outcomes.

\section{References}

1. $\quad$ Allen, Bruce C. "What Does It Take?”, California CPA, May 2001.

2. Cumming, John \& Rankin, Larry J. "150 Hours: A Look Back", Journal of Accountancy April 1999.

3. Gabbin, Alexander L. "The crisis in accounting education; the CPA's role in attracting the best and the brightest to the profession". Journal of Accountancy April 2002.

4. McCrary, Deanna, "Where have all the accounting students gone?", California CPA June 2001.

5. Metrejean, Cheryl T. "Bring the real world to the classroom", Journal of Accountancy October 2001.

6. Person, Stanley "Accounting Education: Charting the Course Through A Perilous Future", Journal of Accountancy April 2002. 